\section{Design and Preliminary Evaluation of a New Ankle Foot Orthosis on Kinetics and Kinematics parameters for Multiple Sclerosis Patients}

\author{
Keyvani Hafshejani A. ${ }^{1 \oplus}$, Aminian Gh. ${ }^{2 * \odot}{ }^{\oplus}$, Azimian M. ${ }^{3}$, Bah- \\ ramizadeh M. ${ }^{2}$, Safaeepour Z. ${ }^{2}$, Biglarian A. ${ }^{4}$, Keivani M. ${ }^{5}$
}

\begin{abstract}
Background: The damage of the central nervous system due to Multiple Sclerosis (MS) leads to many walking disorders in this population. However, current anklefoot orthoses prescribed for improving walking disorders for these patients are not clinically cost-efficient.
\end{abstract}

Objective: This study aimed to design and fabricate a dynamic ankle foot orthosis and a new spring-damper joint mechanism that could adapt the walking problems of MS patients and evaluate the immediate effect of the new orthosis on the speed, range of motion, moment, total work and ground reaction force during walking.

Material and Methods: In this case-series study, after the design and fabrication of a new orthosis, the kinetics and kinematics of walking of four patients with MS were assessed in a case series study.

Results: Walking speed improved with the new orthosis in two participants. The sagittal range of motion (ROM) increased for most of the participants. The sagittal moments increased for hip, knee and ankle joints in most of the measurements. The total joint work showed noticeable difference in the ankle joint. The increased values of vertical component of the ground reaction force (VGRF) were negligible and the increase in the impulse of VGRF was noticeable for only one participant.

Conclusion: The new orthosis had positive effects kinetic and kinematic parameters of walking such as the increased velocity by two subjects and also a more normal sagittal ROM, moment and work, suggesting the potential usefulness of the new orthotic device for MS population.

Citation: Keyvani Hafshejani A, Aminian Gh, Azimian M, Bahramizadeh M, Safaeepour Z, Biglarian A, Keivani M. Design and Preliminary Evaluation of a New Ankle Foot Orthosis on Kinetics and Kinematics parameters for Multiple Sclerosis Patients. J Biomed Phys Eng. nary Evaluation of a New Ankle Foot Orthosis on Kine

\section{Keywords}

Multiple Sclerosis; Kinetics; Kinematics; Ankle-Foot Orthosis; Gait

\section{Introduction}

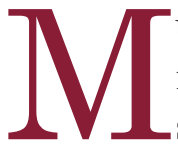

ultiple sclerosis (MS) is a chronic autoimmune disease, leading to demyelination of the central nervous system (CNS) and severe neurological disability [1-3]. The patients experience motor, sensory and cognitive impairments; the impairment of proprioception is more frequent than other sensory inputs $[4,5]$. The CNS pathology is associated with decreased muscle tone or spasticity of foot and ankle muscles, resulting in limited range of motion (ROM) of hip, knee
${ }^{1}$ PhD Candidate, Or-

thotics and Prosthetics

Department, University

of Social Welfare and

Rehabilitation Sciences,

Tehran, Iran

${ }^{2}$ PhD, Orthotics and

Prosthetics Department,

University of Social Wel-

fare and Rehabilitation

Sciences, Tehran, Iran

${ }^{3} \mathrm{MD}$, MS Clinic, Rofei-

deh Hospital, University

of Social Welfare and

Rehabilitation Sciences,

Tehran, Iran

${ }^{4} \mathrm{PhD}$, Department

of Biostatistics and

Epidemiology, Social

Determinants of Health

Research Sciences, Uni-

versity of Social Welfare

and Rehabilitation Sci-

ences, Tehran, Iran

${ }^{5} \mathrm{MD}$, Department of

Radiology, Shahrekord

University of Medical Sci-

ences, Shahrekord, Iran

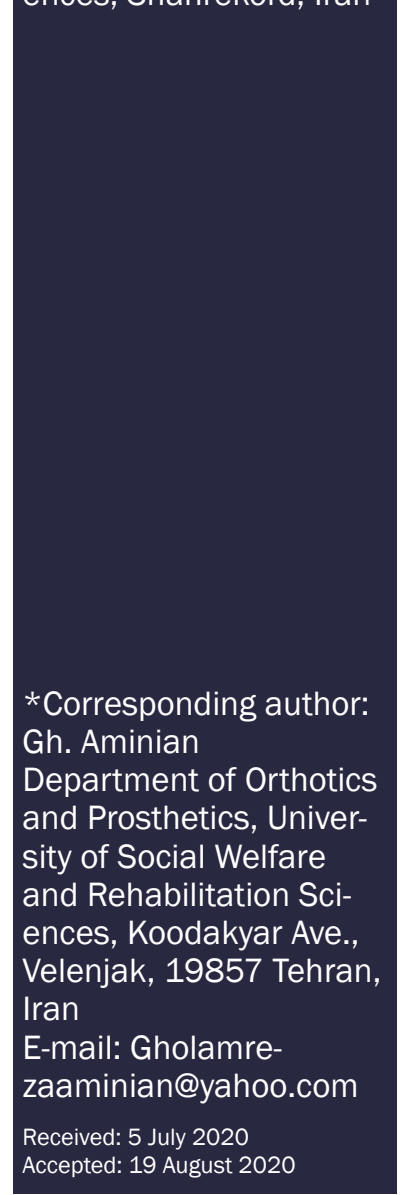

Accepted: 19 August 2020 
and ankle joints, decreased ankle power and poor push-off, drop foot or toe-drag at swing phase and also decreased speed of walking [6, 7]. Therefore, the patient's mobility and ability to do activities of daily living, functional independence, and quality of life are affected extensively [8-11]. Proprioception impairment is associated with balance impairment [5]. About $85 \%$ of MS patients complain of walking impairment and need to mobility aids such as functional electrical stimulation (FES) and ankle-foot orthosis (AFO) $[12,13]$.

The passive AFO is a simple plastic polypropylene device, controlling ankle motion [14]. The most ankle control is provided by solid AFO, which limits all of the ankle motions while the least control is provided by the posterior leaf spring AFO (PLS). The use of solid AFO by MS patients improves toe clearance, but it has unacceptable outcomes such as decreased walking speed, dynamic balance and pain followed by skin irritation [15-17]. Walking by PLS may improve walking speed, but this orthosis has limited application only for non-spastic patients [18, 19]. The functional electrical stimulation of the peroneal nerve may improve walking by the increase of speed, ROM, and decrease exertion level [16, 20, 21]. Renfrew et al., compared the clinical and cost-effectiveness of using solid AFO and FES on function and energy cost of walking of MS population immediately and after one year of using each one $[13,16]$. They found improvement in walking speed and decrease in oxygen cost of walking for both interventions. However, the effects of FES have been assessed immediately and the effects of solid AFO have been investigated after 12 months. They concluded that the use of FES is more cost-efficient. The MS population who used FES reported limitations in design and application, electrode positioning and financial implications of FES [22]. However, the functionality and comfort of orthotic devices have much importance for the MS population, and it seems a new orthotic design with an imme- diate clinical improvement of kinetic and kinematic parameters is needed [15].

The dynamic AFOs are another type of AFOs which allows ankle motions in the sagittal plane and could help to ankle movement by employing spring-damper mechanism [23]. Since the ankle-foot movements in the sagittal plane are associated with frontal plane movements, a motion variance of anatomic and orthotic joints is inevitable and there is also a none-accordance between mechanical and anatomical ankle movements, leading to translation of dynamic AFO on the tissue [24]. Moreover, the MS population walk slow and have less capability to accommodate environmental barriers; therefore, the fitness of orthotic joint action with their speed of walking is necessary [25]. The orthosis should also compensate for the lack of ankle proprioception. Therefore, the aims of the current study were as follows: a) to design and fabricate a new a dynamic AFO with a speed adoptable spring-damper mechanism which accommodates to ankle motion and provides feedback and b) to examine the immediate effect of using the new orthotic device on walking speed and kinetic parameters of MS population.

\section{Material and Methods}

\section{Subjects}

Four MS volunteers accept to participate in this case series study. The inclusion criteria were as following: the age of 20-50, the ability to walk independently for at least 20 meters, the ability to stand on tiptoes, the maximum spasticity of grade II (Ashworth scale) with plantar flexor muscles, the MS disease progression at the first relapsing-remitting stage and the extended disability scale of 4 to 6 . The exclusion criteria were low dynamic balance based on the Timed Up and Go test, any history of the cardiac-respiratory disease and fixed flexion contracture of the hip, knee and ankle joints. The patient recruitment was from July to September in 2019 from the Sina Hospital, 
A New Ankle Foot Orthotic for Multiple Sclerosis Patients

Tehran, Iran. The ethics committee of the University of Social Welfare and Rehabilitation Sciences, Tehran, Iran approved the study (reference number: IR.USWR.REC.1398.072). All participants were agreed and signed the informed consent form.

\section{Intervention}

The new dynamic AFO designed for this study had two parts of the footplate and a shell for shin (Figure 1). The new orthotic ankle joint connected the two parts. The orthotic ankle joint was equipped with these components: a spring-damper mechanism, a rail mechanism to accommodate with anatomical ankle joint, a rail and wagon mechanism to remind proper push-off time, a rattler mechanism to provide environmental feedback of ankle position to the patient and an eye bearing and flat spring. There were two springs with different hardness coefficients, a harder spring to help push-off, and a less hard spring for returning

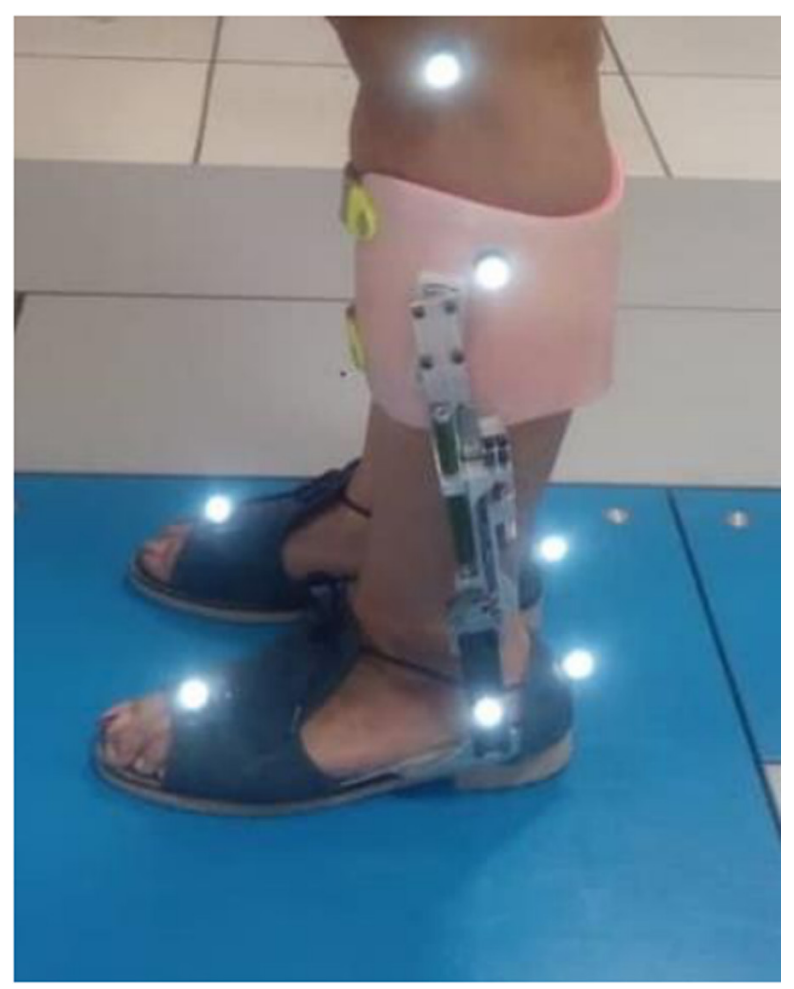

Figure 1: The new ankle-foot orthosis (AFO) designed at this study. the ankle joint to neutral position at the swing phase (Figure 2a).

The outer edge of the damper was threaded and the clinician could adjust the amount of energy damping and speed of walking based on the patient's need (Figure 2a). The orthotic ankle joint was equipped with a rail mechanism, resulting in orthotic accommodation with sagittal movements of the anatomical ankle joint (Figure 2b). Each spring and the damper had a retainer (Figure $2 \mathrm{a}$ ). The retainers were connected with a fine rail and two wagons to each other; therefore, the retainers could slide to each other (Figure 2c). The sliding led to the movement of the spring and damper in relation of each other. The rail and wagon mechanism aimed to remind proper push-off time. The rattler mechanism consisted of a bigger geared rack, a smaller geared rack, and a small spring

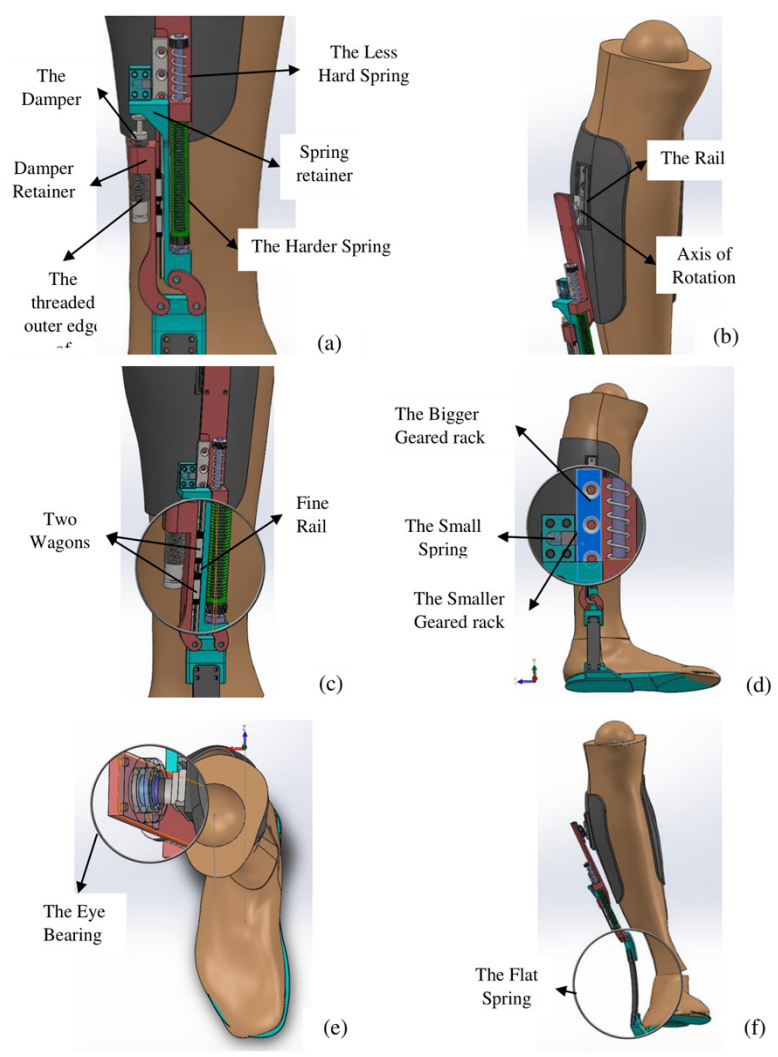

Figure 2: a) Spring-damper mechanism, b) the rail for accommodation, c) the retainers, d) the fine rail and wagons, e) the rattler mechanism, f) the flat spring 
(Figure 2d). When the orthotic joint moves, the two-geared rack would slide on each other. Then the small spring and the smaller geared rack would be pulled back and placed on the next gear. The saved energy of small spring speeds up returning to a neutral position and makes a tiny sound due to vibration. The vibration is proportional to the range of plantarflexion/dorsiflexion and provides feedback. The eye bearing and flat spring (Figures $2 \mathrm{e}$ and $\mathrm{f}$ ) provide three-dimensional movements in all cardinal planes.

\section{Data Collection}

A pair of new AFO (Figure 1) was designed and fabricated for each participant. Each participant walked 10 min with her orthosis to accommodate with the orthosis. Then forty-two ultra-violet markers were attached based on the model stated for the Visual 3D software to the patient's anatomical landmarks. There were single anatomical landmarks such as xiphoid process, the $7^{\text {th }}$ cervical vertebra, the sacrum, and bilateral landmarks such as forehead sides and the acromion process, anterior superior iliac spine, posterior superior iliac spine, medial and lateral sides of knee joint, medial and lateral malleoli, back of the calcaneus, the head of first and fifth metatarsus and hallux for both right as well as left sides. Four marker clusters were also attached to anterior-lateral sides of both thigh and shin for both right and left sides. The patient walked in a 10 meters distance in two situations of with/without the new orthosis. The tests were in random order and the patients had $10 \mathrm{~min}$ of rest between tests. Each data collection was repeated three to six times. The data collection was done at the biomechanical laboratory of the Movaghian Research Centre of Intelligent Neuro-Rehabilitation Technologies, Tehran, Iran. The Vicon ${ }^{\circledR}$ motion analysis system with six ultraviolet cameras and two force platforms were used for kinetic and kinematic evaluations; both systems are highly valid and reliable [26, 27].

\section{Data Analysis}

The main variables of this study were walking speed, sagittal ROM, moment and total work of the hip, knee and ankle joints, vertical component of the ground reaction force (VGRF) and impulse of VGRF. The data were processed using the Nexus software, version 2.9. Then the data of one stride was selected to extract the critical values using the Excel software, version 2016. The sum of the absolute value of the area under the power plot was calculated to assess the total work. The area under the VGRF plot was also calculated to assess the impulse of VGRF. Finally, the data were evaluated for each participant.

\section{Results}

Among $30 \mathrm{MS}$ patients, four females with bilateral involvement were employed for this study after interviewing and assessing. Their demographic information is stated in Table 1.

\section{Subject 1}

The participant walked with a back knee which decreased somewhat by using the or-

Table 1: The demographic information of participants

\begin{tabular}{ccccc} 
Subject number & Age (year) & Weight $\mathbf{( k g )}$ & Height (centimeter) & MS duration (year) \\
\hline $\mathbf{1}$ & 38 & 63 & 159 & 13 \\
\hline $\mathbf{2}$ & 41 & 45.5 & 164 & 11 \\
\hline $\mathbf{3}$ & 36 & 74 & 170 & 15 \\
\hline $\mathbf{4}$ & 35 & 92 & 171 & 16
\end{tabular}


A New Ankle Foot Orthotic for Multiple Sclerosis Patients

thosis. Her walking speed decreased by $27 \%$. The range of all motion increased especially hip flexion and ankle dorsiflexion; (Table 2). The moments of hip extension, knee flexion, and both of ankle plantarflexion/dorsiflexion increased. The increase of total work was negligible for hip and knee joints (less than 25\%) but noticeable (174\%) for ankle joint (Table $3)$. The increase of VGRF was also negligible (less than 15\%) and the increase of impulse of VGRF was $30.62 \%$.

\section{Subject 2}

Their walking speed decreased by $19 \%$. The

Table 2: The kinematic parameters of walking speed sagittal range of motion (ROM)

\begin{tabular}{|c|c|c|c|c|c|}
\hline & & $\begin{array}{l}\text { Subject } \\
\text { number }\end{array}$ & Without Orthosis & With Orthosis & $\begin{array}{c}\text { Percentage of } \\
\text { Differences }\end{array}$ \\
\hline \multirow{4}{*}{\multicolumn{2}{|c|}{ Walking speed (m/s) }} & 1 & 0.48 & 0.35 & -27 \\
\hline & & 2 & 0.68 & 0.49 & -19 \\
\hline & & 3 & 0.26 & 0.51 & 49.01 \\
\hline & & 4 & 0.61 & 0.71 & 10 \\
\hline \multirow{8}{*}{ Hip } & \multirow{4}{*}{ Flexion (degree) } & 1 & 4.52 & 11.59 & 154.87 \\
\hline & & 2 & 28.13 & 24.73 & -12.09 \\
\hline & & 3 & 46.27 & 29.94 & -35.29 \\
\hline & & 4 & 1.30 & 5.78 & 344.62 \\
\hline & \multirow{4}{*}{$\begin{array}{l}\text { Extension } \\
\text { (degree) }\end{array}$} & 1 & 29.42 & 30.28 & 2.92 \\
\hline & & 2 & 9.55 & 11.68 & 22.30 \\
\hline & & 3 & * & - & - \\
\hline & & 4 & 27.79 & 32.30 & 16.23 \\
\hline \multirow{8}{*}{ Knee } & \multirow{4}{*}{ Flexion (degree) } & 1 & 15.26 & 18.10 & 18.61 \\
\hline & & 2 & 38.33 & 45.82 & 19.54 \\
\hline & & 3 & 23.71 & 12.37 & -47.83 \\
\hline & & 4 & 8.41 & 28.49 & 238.76 \\
\hline & \multirow{4}{*}{$\begin{array}{c}\text { Extension } \\
\text { (degree) }\end{array}$} & 1 & 19.15 & 10.64 & -44.44 \\
\hline & & 2 & 4.24 & 2.92 & -31.13 \\
\hline & & 3 & - & - & - \\
\hline & & 4 & 18.86 & 10.58 & -43.90 \\
\hline \multirow{8}{*}{ Ankle } & \multirow{4}{*}{$\begin{array}{l}\text { Plantar flexion } \\
\text { (degree) }\end{array}$} & 1 & 15.63 & 20 & 27.96 \\
\hline & & 2 & 13.43 & 0.10 & -99.26 \\
\hline & & 3 & 13.97 & 18.40 & 31.71 \\
\hline & & 4 & 24.30 & 9.19 & -62.18 \\
\hline & \multirow{4}{*}{$\begin{array}{c}\text { Dorsiflexion } \\
\text { (degree) }\end{array}$} & 1 & 9.79 & 15.8 & 61.39 \\
\hline & & 2 & 6.37 & 11.60 & 83.10 \\
\hline & & 3 & 15.52 & 18.24 & 17.53 \\
\hline & & 4 & 7.01 & 11.52 & 64.34 \\
\hline
\end{tabular}

*The values were not extractable 
Keyvani Hafshejani A., Aminian Gh., Azimian M. et al

Table 3: The Sagittal kinetic parameters of Moment (N.M) and total work (J)

\begin{tabular}{|c|c|c|c|c|c|c|}
\hline & & & $\begin{array}{l}\text { Subject } \\
\text { number }\end{array}$ & $\begin{array}{l}\text { Without } \\
\text { Orthosis }\end{array}$ & With Orthosis & $\begin{array}{c}\text { Percentage of } \\
\text { Differences }\end{array}$ \\
\hline \multirow{28}{*}{$\begin{array}{l}\text { Sagittal Mo- } \\
\text { ment (N.m) }\end{array}$} & \multirow{8}{*}{ Hip } & \multirow{4}{*}{ Flexion (N.m) } & 1 & -260.14 & -172.41 & -33.72 \\
\hline & & & 2 & -168.52 & -258.54 & 53.42 \\
\hline & & & 3 & -417.01 & -405.54 & 2.75 \\
\hline & & & 4 & -271.93 & -256.98 & -5.5 \\
\hline & & \multirow{4}{*}{ Extension (N.m) } & 1 & 540 & 757.11 & 40.21 \\
\hline & & & 2 & 409.8 & 317.58 & -22.5 \\
\hline & & & 3 & 315.25 & 373.43 & 18.46 \\
\hline & & & 4 & 561.97 & 581.45 & 3.47 \\
\hline & \multirow{12}{*}{ Knee } & \multirow{4}{*}{ First peak (N.m) } & 1 & -58.97 & -955.91 & 1521.01 \\
\hline & & & 2 & 280.96 & 255.63 & -9.02 \\
\hline & & & 3 & 443.04 & 396.79 & -10.44 \\
\hline & & & 4 & -395.98 & -943.30 & 138.22 \\
\hline & & \multirow{4}{*}{ Midstance minima (N.m) } & 1 & -170.12 & -767.52 & 351.16 \\
\hline & & & 2 & -262.53 & -303.46 & 15.59 \\
\hline & & & 3 & 209.52 & 230.84 & 10.18 \\
\hline & & & 4 & -333.55 & -737.01 & 120.96 \\
\hline & & \multirow{4}{*}{ Second Peak (N.m) } & 1 & -336.39 & -834.38 & 148.04 \\
\hline & & & 2 & 160.08 & 154.79 & -3.30 \\
\hline & & & 3 & 249.27 & 347.41 & 39.38 \\
\hline & & & 4 & -353.90 & -836.34 & 136.32 \\
\hline & \multirow{8}{*}{ Ankle } & \multirow{4}{*}{ Dorsiflexion (N.m) } & 1 & -66.86 & -15.57 & -76.71 \\
\hline & & & 2 & -240.60 & -99.29 & -58.73 \\
\hline & & & 3 & -102.15 & -53.45 & -47.67 \\
\hline & & & 4 & -40.81 & -69.62 & 70.60 \\
\hline & & \multirow{4}{*}{ Plantar Flexion (N.m) } & 1 & 446.08 & 959.28 & 115.05 \\
\hline & & & 2 & 340.69 & 1211.78 & 255.45 \\
\hline & & & 3 & 751.31 & 892.29 & 18.76 \\
\hline & & & 4 & 346.15 & 1112.73 & 221.46 \\
\hline \multirow{12}{*}{$\begin{array}{l}\text { Sagittal total } \\
\text { work (J) }\end{array}$} & \multirow{4}{*}{\multicolumn{2}{|c|}{ Hip }} & 1 & 5.33 & 6.05 & 13.51 \\
\hline & & & 2 & 2.19 & 4.26 & 94.52 \\
\hline & & & 3 & 4.53 & 6.29 & 38.85 \\
\hline & & & 4 & 5.36 & 6.11 & 13.99 \\
\hline & \multirow{4}{*}{\multicolumn{2}{|c|}{ Knee }} & 1 & 5.01 & 6.22 & 24.15 \\
\hline & & & 2 & 1.90 & 2.61 & 37.37 \\
\hline & & & 3 & 1.67 & 2.93 & 75.45 \\
\hline & & & 4 & 9.04 & 7.01 & -22.46 \\
\hline & \multirow{4}{*}{\multicolumn{2}{|c|}{ Ankle }} & 1 & 4.49 & 12.56 & 179.73 \\
\hline & & & 2 & 1.54 & 5.74 & 272.73 \\
\hline & & & 3 & 3.63 & 7.15 & 112.8 \\
\hline & & & 4 & 3.57 & 6.72 & 88.24 \\
\hline
\end{tabular}


range of hip extension, knee extension, and ankle dorsiflexion increased, but the range of hip flexion, knee extension, and ankle plantarflexion decreased (Table 2). The moments of all motions decreased except for ankle plantar flexion which increased by $255.45 \%$. The moment of hip flexion and ankle dorsiflexion had a noticeable decrease. The increase of total work was noticeable especially for the ankle joint (Table 3). The critical points of the VGRF plot were unclear. As a whole, the increase of the first peak of VGRF was negligible (less than 10\%); however, the increase of impulse of VGRF was noticeable (Table 4).

\section{Subject 3}

Their walking speed increased noticeably. The range of hip and knee flexion decreased; however, the range of ankle dorsiflexion and plantarflexion increased that all of the changes were less than $50 \%$ (Table 2). The moments of hip flexion, the first peak of knee flexion, and ankle dorsiflexion decreased and the moments of other motions increased that all of the changes were less than 50\% (Table 3). The total work increased for all of the joints and the increase was noticeable for both of the knee and ankle joints (Table 3). The critical points of VGRF decreased negligibly. The increase in the impulse of VGRF was also negligible (less than 12\%).

\section{Subject 4}

Their walking speed increased somewhat. The range of all motions increased except for knee extension and ankle plantar flexion. The increased range of flexion for hip and knee joints and ankle dorsiflexion was noticeable (more than 50\%) (Table 2). The moments of all motions increased except for hip flex-

Table 4: The critical values of vertical component of the ground reaction force (VGRF) and the impulse of VGRF

\begin{tabular}{|c|c|c|c|c|c|}
\hline & & $\begin{array}{l}\text { Subject } \\
\text { number }\end{array}$ & $\begin{array}{l}\text { Without } \\
\text { Orthosis }\end{array}$ & With Orthosis & $\begin{array}{c}\text { Percentage of } \\
\text { Differences }\end{array}$ \\
\hline \multirow{12}{*}{ VGRF (N.m) } & \multirow{4}{*}{$\begin{array}{l}\text { First peak } \\
\text { (N.m) }\end{array}$} & 1 & 10.63 & 11.11 & 4.52 \\
\hline & & 2 & 9.37 & 10.13 & 8.11 \\
\hline & & 3 & 10.30 & 10.22 & -0.78 \\
\hline & & 4 & 10.73 & 11.63 & 8.39 \\
\hline & \multirow{4}{*}{$\begin{array}{c}\text { Midstance } \\
\text { minima (N.m) }\end{array}$} & 1 & 7.96 & 9.02 & 13.32 \\
\hline & & 2 & - & - & - \\
\hline & & 3 & 9.59 & 9.50 & -0.94 \\
\hline & & 4 & 9.26 & 9.18 & -0.86 \\
\hline & \multirow{4}{*}{$\begin{array}{l}\text { Second Peak } \\
\text { (N.m) }\end{array}$} & 1 & 9.56 & 10.20 & 6.70 \\
\hline & & 2 & - & - & - \\
\hline & & 3 & 9.61 & 9.66 & 0.52 \\
\hline & & 4 & 10.29 & 10.53 & 2.33 \\
\hline \multirow{4}{*}{\multicolumn{2}{|c|}{ Impulse of VGRF (N.s) }} & 1 & 139.44 & 182.14 & 30.62 \\
\hline & & 2 & 100.71 & 187.21 & 85.89 \\
\hline & & 3 & 257.25 & 287.60 & 11.80 \\
\hline & & 4 & 195.58 & 197.76 & 1.12 \\
\hline
\end{tabular}


ion with a negligible decrease of $5.5 \%$. The increase of moments was noticeable for both knee and ankle joints (Table 3 ). The total work increased for the hip and ankle joints; in addition, the increase was noticeable in the ankle joint. The total work of knee joint decreased somewhat (Table 3). The critical points of VGRF increase negligibly (less than 10\%). The increase in the impulse of VGRF was also negligible (less than $1.12 \%$ ).

\section{Discussion}

The case series study examined the immediate effects of a new mechanical AFO on kinematics and kinetic parameters designed based on the needs of the MS population. The results of the study showed that the new orthosis improved the walking speed of two participants, the sagittal ROM increased for most of the participants and the sagittal moments increased for hip, knee, and ankle joints in most of the measurements. The results also showed noticeable difference in total joint work in the ankle joint. The increased values of VGRF were negligible and the increase in the impulse of VGRF was noticeable for only one participant. Therefore, it seems the new orthosis has the potential to help the walking ability of the MS population.

Renfrew et al., stated MS patients need to use solid AFO at least 12 months to assess a significant increase in walking speed [13]. In this study, walking by the new orthosis led to increasing speed of walking for two participants, and decreasing speed less than $30 \%$ for the other two participants. Subject 4 walked $49 \%$ faster with the new AFO. This may be due to increase ankle ROM and moment, decreased hip flexion, lesser back knee, and a noticeable increase of knee flexion [28]. The decreased speed of walking for subject one may be due to the increased mid-stance minima of VGRF [29]. Walking with new orthotic devices led to an increased range of hip extension, ankle dorsiflexion, and knee flexion for all participants. The decrease of knee exten- sion or back knee was a desirable outcome. These verify the usefulness of spring mechanism equipped for reminding push-off, the rail mechanism equipped for accommodation to sagittal movements and the rattler mechanism.

The sagittal moments increased for the most of the parameter comparison, especially for ankle plantar flexion. The total sagittal work increased for all of the joints that the most and least incremental total sagittal work was observed for the ankle joint and the hip joint, respectively. This was in contrast to the findings of Bregman et al., who analyzed the effects of walking by spring AFO [30]. It seems the more possible range of motion with the new AFO leads to more power generation and absorption with the ankle joint. The limited increase of the second peak of VGRF contradicts the diminished behavior of the MS population at the terminal stance $[6,28]$. The increase of VGRF impulse was negligible for two subjects, but it was noticeable for subject 2 . The few increases of total vertical force could verify the effects of customized damping, eye bearing, and flat spring mechanism.

This study didn't compare the effect of new AFO with common interventions of FES and simple passive AFOs; such comparisons may help to better decision making concerning the clinical and cost-effectiveness of the intervention. This study only evaluated the immediate effects of new AFO and the longterm effects may be different and have better results. Therefore, it is suggested that a longterm study is performed using this new AFO for these patients in the future. If the patients walked with a predefined speed, it was possible to have better evaluation of the orthosis effect on moments and power [31].

\section{Conclusion}

The mixed effect of spring-damper, rail, and wagons to accommodate orthotic motions with physiologic ankle joint, rattler mechanism, flat spring and, eye bearing led to acceptable immediate effects on kinetic and kinematic 
parameters of walking. It seems, by matching orthosis to patient's demands, mechanical orthosis has the potential to have a challenge with FES.

\section{Acknowledgment}

The authors would like to thank the staff of the biomechanical laboratory of the Movaghian Research Centre of Intelligent Neuro-Rehabilitation Technologies, Tehran, Iran.

\section{Conflict of Interest}

None

\section{References}

1. Berto P, Amato M, Bellantonio P, Bortolon F, Cavalla $P$, Florio $C$, et al. The direct cost of patients with multiple sclerosis: a survey from Italian MS centres. Neurol Sci. 2011;32(6):1035-41. doi: 10.1007/s10072-011-0578-4. PubMed PMID: 21505911.

2. Amato MP, Battaglia MA, Caputo D, Fattore G, Gerzeli S, Pitaro M, et al. The costs of multiple sclerosis: a cross-sectional, multicenter cost-of-illness study in Italy. J Neurol. 2002;249(2):152-63. doi: 10.1007/pl00007858. PubMed PMID: 11985380.

3. Wallin MT, Culpepper WJ, Nichols E, Bhutta ZA, Gebrehiwot TT, Hay SI, et al. Global, regional, and national burden of multiple sclerosis 1990-2016: a systematic analysis for the Global Burden of Disease Study 2016. Lancet Neurol. 2019;18(3):269-85. doi: $10.1016 /$ S1474-4422(18)30443-5. PubMed PMID: 30679040 . PubMed PMCID: PMC6372756.

4. Gehlsen G, Whaley M. Falls in the elderly: part II, Balance, strength, and flexibility. Arch Phys Med Rehabil. 1990;71:739-41. PubMed PMID: 2403279.

5. Jamali A, Sadeghi-Demneh E, Fereshtenajad N, Hillier S. Somatosensory impairment and its association with balance limitation in people with multiple sclerosis. Gait Posture. 2017;57:224-9. doi: 10.1016/j.gaitpost.2017.06.020. PubMed PMID: 28667904.

6. Kelleher KJ, Spence W, Solomonidis S, Apatsidis D. The characterisation of gait patterns of people with multiple sclerosis. Disabil Rehabi. 2010;32(15):1242-50. doi: 10.3109/09638280903464497. PubMed PMID: 20156050.

7. Klewer J, Pohlau D, Nippert I, Haas J, Kugler J. Problems reported by elderly patients with mul- tiple sclerosis. J Neurosci Nurs. 2001;33(3):16771. doi: 10.1097/01376517-200106000-00009. PubMed PMID: 11413662.

8. Kohn CG, Baker WL, Sidovar MF, Coleman CI. Walking Speed and Health-Related Quality of Life in Multiple Sclerosis. Patient. 2014;7:55-61. doi: 10.1007/s40271-013-0028-x. PubMed PMID: 24078332.

9. Einarsson U, Gottberg K, Fredrikson S, Koch LV, Holmqvist LW. Activities of daily living and social activities in people with multiple sclerosis in Stockholm County. Clin Rehabil. 2006;20(6):543-51. doi: 10.1191/0269215506cr953oa. PubMed PMID: 16892936.

10. Corry M, While A. The needs of carers of people with multiple sclerosis: A literature review. Scand Caring Sci. 2009;23(3):569-88. doi: 10.1111/j.14716712.2008.00645.x. PubMed PMID: 19077062.

11. Dunn J. Impact of mobility impairment on the burden of caregiving in individuals with multiple sclerosis. Expert Rev Pharmacoeconomics Outcomes Res. 2010;10(4):433-40. doi: 10.1586/erp.10.34. PubMed PMID: 20482233.

12. LaRocca NG. Impact of Walking Impairment in Multiple Sclerosis, Perspectives of Patients and Care Partners. Patient. 2011;4(3):189-201. doi: 10.2165/11591150-000000000-00000. PubMed PMID: 21766914.

13. Renfrew L, Paul L, McFadyen A, Rafferty D, Moseley 0 , Lord AC, et al. The clinical- and cost-effectiveness of functional electrical stimulation and ankle-foot orthoses for foot drop in Multiple Sclerosis: a multicentre randomized trial. Clin Rehabil. 2019;33(7):1150-62. doi: 10.1177/0269215519842254. PubMed PMID: 30974955.

14. Chui K, Jorge M, Yen S-C, Lusardi M. Orthotics and Prosthetics in Rehabilitation. Missouri: Elsevier Health Sciences; 2019. p. 227-32.

15. Swinnen E, Lefeber N, Werbrouck A, Gesthuizen $Y$, Ceulemans L, Christiaens S, et al. Male and female opinions about orthotic devices of the lower limb: A multicentre, observational study in patients with central neurological movement disorders. NeuroRehabilitation. 2018;42(1):121-30. doi: 10.3233/ NRE-172214. PubMed PMID: 29400677.

16. Renfrew L, Lord AC, McFadyen AK, Rafferty $D$, Hunter R, Bowers R, et al. A comparison of the initial orthotic effects of functional electrical stimulation and ankle-foot orthoses on the speed and oxygen cost of gait in multiple sclerosis. J Rehabil Assist Technol Eng. 2018;5:1-9. doi: 10.1177/2055668318755071. 
Keyvani Hafshejani A., Aminian Gh., Azimian M. et al

17. Cattaneo D, Marazzini F, Crippa A, Cardini R. Do static or dynamic AFOs improve balance? Clin Rehabil. 2002;16(8):894-9. doi: 10.1191/0269215502cr5470a. PubMed PMID: 12501952.

18. Hsu JD, Michael J, Fisk J. AAOS Atlas of Orthoses and Assistive Devices E-Book: Elsevier Health Sciences; 2008.

19. Bregman DJ, De Groot V, Van Diggele P, Meulman H, Houdijk H, Harlaar J. Polypropylene ankle foot orthoses to overcome drop-foot gait in central neurological patients: a mechanical and functional evaluation. Prosthet Orthot Int. 2010;34(3):293304. doi: 10.3109/03093646.2010.495969. PubMed PMID: 20738233.

20. Sheffler LR, Bailey SN, Chae J. Spatiotemporal and kinematic effect of peroneal nerve stimulation versus an ankle-foot orthosis in patients with multiple sclerosis: a case series. PM\&R. 2009;1(7):604-11. doi: 10.1016/j.pmrj.2009.04.002. PubMed PMID: 19627953

21. Khurana SR, Beranger AG, Felix ER. Perceived Exertion Is Lower When Using a Functional Electrical Stimulation Neuroprosthesis Compared With an Ankle-Foot Orthosis in Persons With Multiple Sclerosis: A Preliminary Study. Am J Phys Med Rehabil. 2017;96(3):133-9. doi: 10.1097/ PHM.0000000000000626. PubMed PMID: 27680426.

22. Bulley C, Mercer TH, Hooper JE, Cowan P, Scott $S$, Van Der Linden ML. Experiences of functional electrical stimulation (FES) and ankle foot orthoses (AFOs) for foot-drop in people with multiple sclerosis. Disabil Rehabil Assist Technol. 2015;10(6):45867. doi: 10.3109/17483107.2014.913713. PubMed PMID: 24796365.

23. Yamamoto S, Ibayashi S, Fuchi M, Yasui T. Immediate-term effects of use of an anklefoot orthosis with an oil damper on the gait of stroke patients when walking without the device. Prosthet Orthot Int. 2015;39(2):140-9. doi: 10.1177/0309364613518340. PubMed PMID: 24469429 .
24. Alam M, Choudhury IA, Mamat AB. Mechanism and design analysis of articulated ankle foot orthoses for drop-foot. Scientific World Journal. 2014;2014:867869. doi: 10.1155/2014/867869. PubMed PMID: 24892102. PubMed PMCID: PMC4032669.

25. Kaipust JP, Huisinga JM, Filipi M, Stergiou N. Gait variability measures reveal differences between multiple sclerosis patients and healthy controls. Motor Control. 2012;16(2):229-44. doi: 10.1123/ mcj.16.2.229. PubMed PMID: 22615327.

26. Windolf M, Gotzen N, Morlock M. Systematic accuracy and precision analysis of video motion capturing systems-exemplified on the Vicon-460 system. J Biomech. 2008;41:2776-80. doi:10.1016/j. jbiomech.2008.06.024.

27. Rogind $H$, Simonsen $H$, Era $P$, Bliddal H. Comparison of Kistler 9861A force platform and Chattecx Balance System for measurement of postural sway: correlation and test-retest reliability. Scand J Med Sci Sports. 2003;13(2):106-14. doi: 10.1034/j.1600-0838.2003.01139.x. PubMed PMID: 12641642.

28. Benedetti M, Piperno R, Simoncini L, Bonato P, Tonini A, Giannini S. Gait abnormalities in minimally impaired multiple sclerosis patients. Mult Scler. 1999;5(5):363-8. doi: 10.1177/135245859900500510. PubMed PMID: 10516781.

29. Neptune RR, Sasaki K. Ankle plantar flexor force production is an important determinant of the preferred walk-to-run transition speed. J Exp Biol. 2005;208(5):799-808. doi: 10.1242/jeb.01435. PubMed PMID: 15755878.

30. Bregman D, Harlaar J, Meskers C, De Groot V. Spring-like Ankle Foot Orthoses reduce the energy cost of walking by taking over ankle work. Gait Posture. 2012;35(1):148-53. doi: 10.1016/j.gaitpost.2011.08.026. PubMed PMID: 22050974.

31. Petrucci MN. Evaluation of gait kinematics and kinetics using a powered ankle-foot orthosis for gait assistance in people with multiple sclerosis. University of Illinois Urbana-Champaign; 2016. 